\title{
Coordination-Chemistry Control of Proton Conductivity in the Iconic Metal-Organic Framework Material HKUST-1
}

\author{
Nak Cheon Jeong, Bappaditya Samanta, Chang Yeon Lee, Omar K. Farha,* and Joseph T. Hupp* \\ Department of Chemistry and International Institute for Nanotechnology, Northwestern University, 2145 Sheridan Road, Evanston, \\ Illinois 60208, United States
}

Supporting Information

\begin{abstract}
HKUST-1, a metal-organic framework (MOF) material containing $\mathrm{Cu}^{\mathrm{II}}$-paddlewheel-type nodes and 1,3,5-benzenetricarboxylate struts, features accessible $\mathrm{Cu}^{\mathrm{II}}$ sites to which solvent or other desired molecules can be intentionally coordinated. As part of a broader investigation of ionic conductivity in MOFs, we unexpectedly observed substantial proton conductivity with the "as synthesized" version of this material following sorption of methanol. Although HKUST-1 is neutral, coordinated water molecules are rendered sufficiently acidic by $\mathrm{Cu}^{\mathrm{II}}$ to contribute protons to pore-filling methanol molecules and thereby enhance the alternatingcurrent conductivity. At ambient temperature, the chemical identities of the node-coordinated and porefilling molecules can be independently varied, thus enabling the proton conductivity to be reversibly modulated. The proton conductivity of HKUST-1 was observed to increase by $\sim 75$-fold, for example, when nodecoordinated acetonitrile molecules were replaced by water molecules. In contrast, the conductivity became almost immeasurably small when methanol was replaced by hexane as the pore-filling solvent.
\end{abstract}

$\mathrm{M}$ etal-organic frameworks (MOFs) are an intriguing class of crystalline materials that can be readily assembled by combining metal ions (components of nodes) and multitopic organic ligands (structural linkers) via coordination chemistry, typically under solvothermal reaction conditions. ${ }^{1}$ Often characterized by large internal surface areas and extended nanoscale porosity, MOFs are being examined as candidate materials for applications in chemical separations, ${ }^{2}$ gas storage, ${ }^{3}$ heterogeneous catalysis, ${ }^{4,5}$ sensing, ${ }^{6}$ ion exchange, ${ }^{7}$ and drug delivery. ${ }^{8}$ Recently, another potential property of MOFs, electrical conductivity-and, in particular, proton conductivity-has begun receiving attention. This attention comes in part from fundamental scientific interest in ionic conductivity $^{9,10}$ in new environments, in part from a desire to use conductivity as a real-time reporter on sorption of molecular guests, ${ }^{11}$ and in part because of the need for new protonconducting materials capable of better performance than existing materials when deployed as membranes in proton exchange membrane (PEM) fuel cells. ${ }^{9}$

To date, only two approaches have been used to engender proton conductivity in MOFs. The first centers on incorporating carboxylic, sulfonic, or phosphonic acid species as channel- accessible functionalities on framework linkers. ${ }^{12}$ The second entails physically introducing proton donors and/or carriers such as ammonium ion, carboxylic acid species, or $1 H-1,2,4-$ triazole into the pores of already-synthesized framework compounds. ${ }^{13}$ Here we report on a third approach: a poor proton donor, in this case $\mathrm{H}_{2} \mathrm{O}$, is bound to an otherwise open coordination site of a node- or linker-based metal cation. Binding substantially increases the acidity of the incorporated molecule, enabling it to donate a proton to hydroxylic guest molecules (in this case $\mathrm{MeOH}$ ) and thereby rendering conductive the network of hydrogen-bonded guest molecules filling the framework material's pores and channels. As shown below, we find that this approach can increase proton conductivity by close to 2 orders of magnitude.

While any of several MOFs featuring open coordination sites $^{3 c, 14}$ should be capable of capitalizing on this new approach, we limited our study to HKUST-1, a nanoporous crystalline material constructed from paddlewheel-coordinated $\left(\mathrm{Cu}^{\mathrm{II}}\right)_{2}$ nodes and 1,3,5-benzenetricarboxylate (BTC) linkers ${ }^{15}$ (Chart

Chart 1. Illustrations of (a) the HKUST-1 Structure in a Two-Dimensional View along the (100) Direction and (b) an HKUST-1 Node with the Cu-Paddlewheel Environment (a)

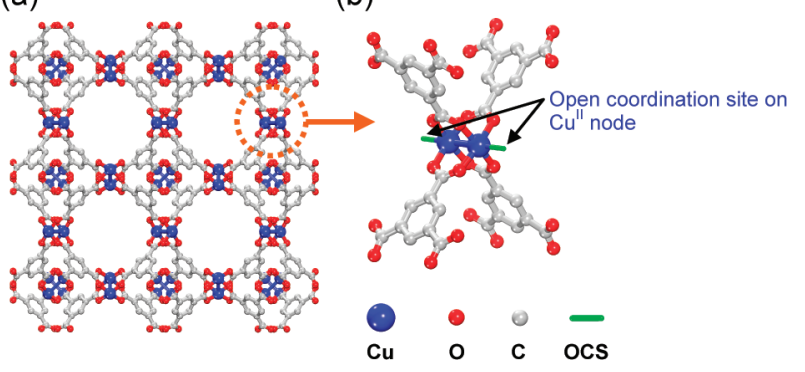

1). The ease of preparation of HKUST-1, together with the presence of weakly axially coordinating $\mathrm{Cu}^{\mathrm{II}}$ sites, ${ }^{16}$ have made it one of the most widely studied MOFs. One intriguing study by Yazaydin and co-workers showed the importance of $\mathrm{Cu}^{\mathrm{II}}$ coordinated water in $\mathrm{CO}_{2}$ adsorption. ${ }^{17}$ Other studies have revealed the importance of the open form of the metal site (obtained by axial-ligand removal) for Lewis acid catalysis ${ }^{5}$ and selective adsorption. ${ }^{18}$ For systematic studies of proton conductivity, we examined the "as synthesized" version of

Received: August 22, 2011

Published: December 12, 2011 
HKUST-1, versions incorporating hydroxylic molecules as axial ligands, and a version incorporating a nonhydroxylic molecule as an axial ligand (Figure 1). Most experiments employed

\section{(a) $\mathrm{H}_{2} \mathrm{O}$ - coordinated $\mathrm{Cu}^{\prime \prime}$}

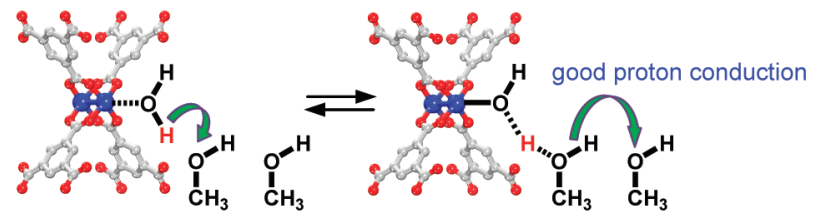

(b) EtOH-coordinated $\mathrm{Cu}^{\prime \prime}$

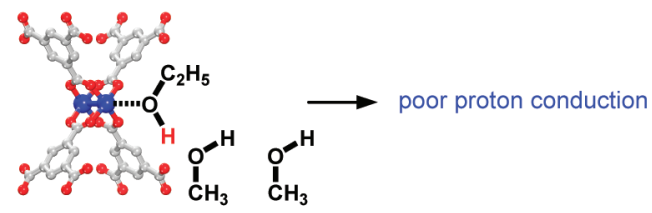

(c) MeCN-coordinated $\mathrm{Cu}^{\prime \prime}$

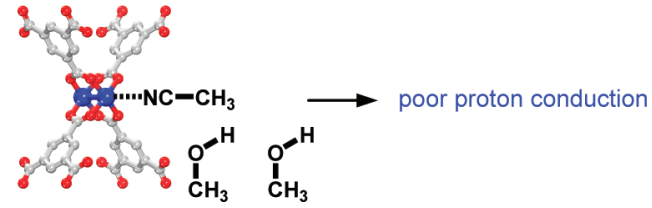

Figure 1. Qualitative representations of proton transfer from $\mathrm{Cu}^{\mathrm{II}}$ centers coordinated with (a) water, (b) ethanol, and (c) acetonitrile.

methanol as the pore-filling solvent, but a few employed hexane. Key to the study was the ability to vary the chemical identities of the copper-coordinated molecules and the remaining channel-filling molecules independently.

"Pristine" HKUST-1 was prepared via solvothermal reaction of copper(II) nitrate and BTC in a mixed solvent of water and ethanol [for details, see section S-1 in the Supporting Information (SI)]. This form contains both $\mathrm{H}_{2} \mathrm{O}$ and EtOH as coordinated molecules. To prepare pure $\mathrm{H}_{2} \mathrm{O}-$, EtOH-, $\mathrm{MeOH}$-, or MeCN-coordinated HKUST-1, both $\mathrm{H}_{2} \mathrm{O}$ and $\mathrm{EtOH}$ were removed via heating at $150{ }^{\circ} \mathrm{C}$ for $48 \mathrm{~h}$ under flowing nitrogen. Samples of the solvent-free material were then placed in an Ar-charged glovebox and allowed to coordinate $\mathrm{H}_{2} \mathrm{O}, \mathrm{EtOH}, \mathrm{MeOH}$, or $\mathrm{MeCN}$ by soaking in the corresponding neat liquid (see the SI). Figure 2a shows ${ }^{1} \mathrm{H}$ NMR spectra of pristine-HK, $\mathrm{H}_{2} \mathrm{O}-\mathrm{HK}, \mathrm{EtOH}-\mathrm{HK}, \mathrm{MeOH}-$ $\mathrm{HK}$, and $\mathrm{MeCN}-\mathrm{HK}$ ( $\mathrm{HK}$ = fully desolvated HKUST-1). The spectra were taken after each sample was dissolved in deuterated sulfuric acid, $\mathrm{D}_{2} \mathrm{SO}_{4}{ }^{19}{ }^{19}$ The peak for three identical protons in BTC appears at $\sim 8.8 \mathrm{ppm}$, while peaks for the two identical $\mathrm{CH}_{2}$ protons and three identical $\mathrm{CH}_{3}$ protons in ethanol appear at 3.90 and $0.83 \mathrm{ppm}$, respectively. Additionally, the peaks for the three identical $\mathrm{CH}_{3}$ protons of $\mathrm{MeOH}$ and $\mathrm{MeCN}$ appear at 3.65 and $1.88 \mathrm{ppm}$, respectively. However, the peak for water protons does not appear since sulfuric acid forms hydronium ions (nominally $\mathrm{H}_{3} \mathrm{O}^{+}$) featuring a peak at $\sim 10.6$ ppm. On the basis of integration of these peaks, we found that $60 \%$ of the coordinated solvent molecules in pristine HKUST-1 were $\mathrm{H}_{2} \mathrm{O}$ and $40 \%$ were $\mathrm{EtOH}$ and that these molecules were completely supplanted by $\mathrm{H}_{2} \mathrm{O}, \mathrm{EtOH}, \mathrm{MeOH}$, or $\mathrm{MeCN}$ in the corresponding modified HKUST-1 materials. The phase purity of pristine-HK, $\mathrm{H}_{2} \mathrm{O}-\mathrm{HK}, \mathrm{EtOH}-\mathrm{HK}, \mathrm{MeOH}-\mathrm{HK}$, and $\mathrm{MeCN}-\mathrm{HK}$ was confirmed via powder X-ray diffraction (PXRD) measurements (Figure 2b). The structural integrity of the MOF was well-preserved following these ligation-based

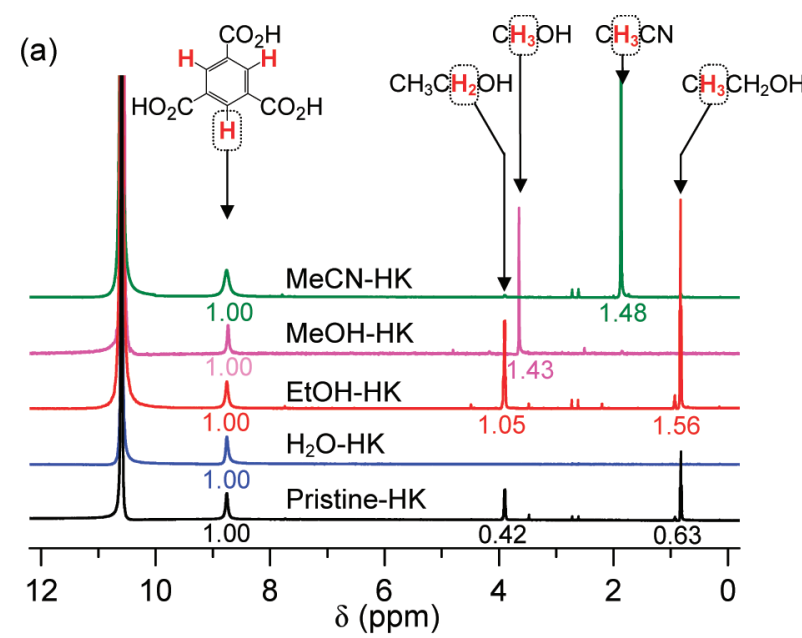

(b)

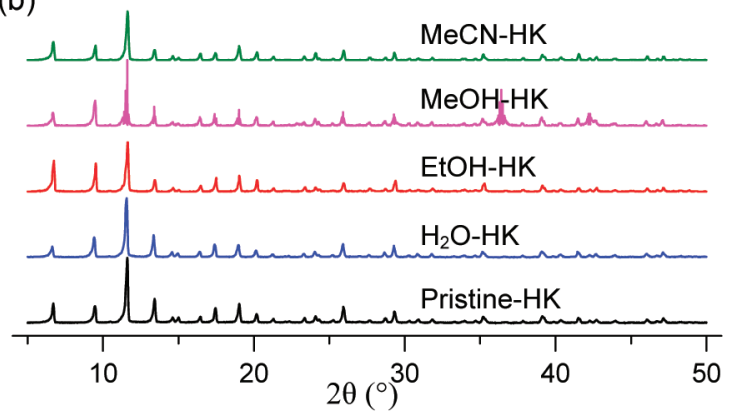

Figure 2. (a) ${ }^{1} \mathrm{H}$ NMR spectra and (b) PXRD patterns of pristine-HK, $\mathrm{H}_{2} \mathrm{O}-\mathrm{HK}$, EtOH-HK, MeCN-HK, and $\mathrm{MeOH}-\mathrm{HK}$ as indicated (We designate desolvated HKUST-1 as HK). The numbers below each spectrum in (a) are relative peak areas.

modifications. For conductivity measurements, disk-shaped pellets of the various versions of HKUST-1 were prepared by using a press and a die measuring $7.6 \mathrm{~mm}$ in diameter and 1.0 $\mathrm{mm}( \pm 0.03 \%)$ in thickness. Silver epoxy was coated on the front and back faces of each pellet and used to anchor a pair of tin-coated copper wires. Each pellet was then placed in an oven at $\sim 60{ }^{\circ} \mathrm{C}$ for $40 \mathrm{~min}$ to cure the epoxy. Pellets were then exposed to methanol vapor (in dry $\mathrm{N}_{2}$ ) at room temperature, after which variable-frequency alternating-current conductivity measurements (impedance measurements) were initiated.

As shown in Figure 3 and section S-2, plots of the imaginary component $\left(Z^{\prime \prime}\right)$ versus the real component $\left(Z^{\prime}\right)$ of the impedance are dominated by a single arc that we ascribe to

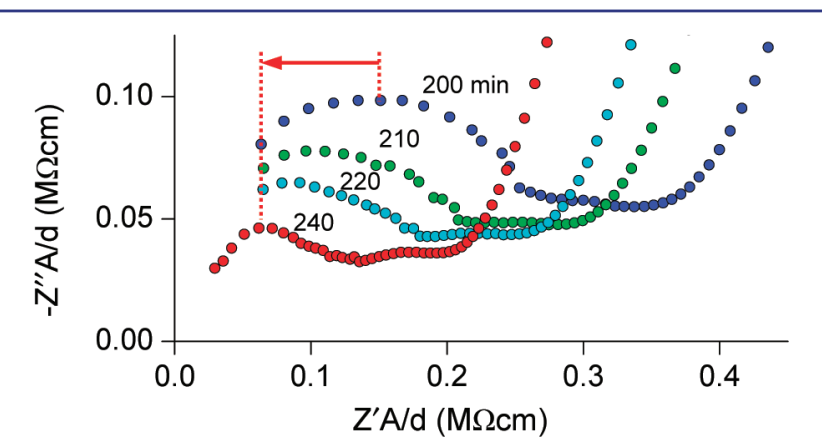

Figure 3. Impedance spectra of a $\mathrm{H}_{2} \mathrm{O}-\mathrm{HK}$ sample following exposure to $\mathrm{MeOH}$ vapor at room temperature. The arrow indicates that conductivity of the sample increases with increasing exposure time. See the SI for additional data. 
proton conduction (for details, see section S-3). Notably, the amplitude of the arc and its maximum along the $Z^{\prime}$ axis shift to progressively smaller values with increasing $\mathrm{MeOH}$ vapor exposure time. That is indicative of increasing conductivity (decreasing resistivity) and is to be expected as the pores slowly fill with $\mathrm{MeOH}$, culminating in constant values for the conductivity. The limiting conductivities for both (hydroxylic) EtOH-HK and (nonhydroxylic) $\mathrm{MeCN}-\mathrm{HK}$ were $0.2 \mu \mathrm{S} \mathrm{cm}^{-1}$. These values are essentially identical to what we measured for carefully dried bulk $\mathrm{MeOH}\left(0.17 \mu \mathrm{S} \mathrm{cm}^{-1}\right.$; see the SI) and only slightly greater than what has been reported previously for highly purified bulk $\mathrm{MeOH}\left(0.04-0.11 \mu \mathrm{S} \mathrm{cm}^{-1}\right) .^{20,21}$ Taken together, these results indicate that neither coordinated acetonitrile nor coordinated EtOH enhances the conductivity within HKUST-1.

In contrast, $\mathrm{H}_{2} \mathrm{O}-\mathrm{HK}$ yielded a conductivity of $15 \mu \mathrm{S} \mathrm{cm}^{-1}$, which is $\sim 90$ times larger than that of bulk $\mathrm{MeOH}$ and $\sim 75$ times larger than those of $\mathrm{EtOH}-\mathrm{HK}$ and $\mathrm{MeCN}-\mathrm{HK}$ (Figure 4). We attribute this striking increase to the participation of

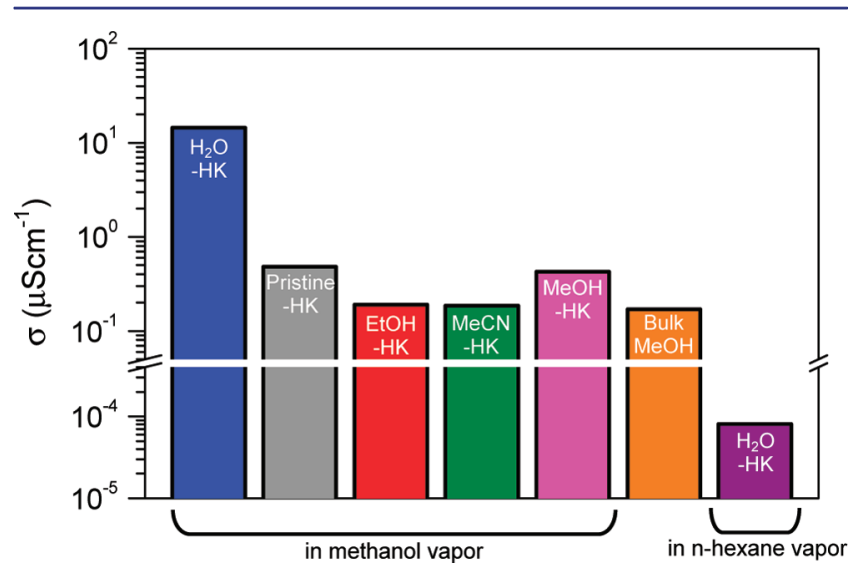

Figure 4. Proton conductivities of $\mathrm{H}_{2} \mathrm{O}-\mathrm{HK}$, pristine- $\mathrm{HK}$, EtOH-HK, $\mathrm{MeCN}-\mathrm{HK}, \mathrm{MeOH}-\mathrm{HK}$, and bulk $\mathrm{MeOH}$ under a $\mathrm{MeOH}$ or $n$-hexane atmosphere as indicated.

coordinated water molecules as proton donors toward methanol, which increases the concentration of $\mathrm{CH}_{3} \mathrm{OH}_{2}^{+}$ well beyond what is achieved solely via autoprotolysis, thereby enhancing the proton conductivity (presumably via Grotthusstype proton transfer, although mechanistic studies of this sort are beyond the scope of this preliminary study). The role of $\mathrm{Cu}^{\mathrm{II}}$ is to enhance the acidity of ligated $\mathrm{H}_{2} \mathrm{O}$, a proposal for which there is ample chemical precedent. ${ }^{22}$

The absence of conductivity enhancement by coordinated $\mathrm{MeCN}$, which lacks a dissociable proton, is understandable and consistent with our interpretation. In the case of ethanol coordination by $\mathrm{Cu}^{\mathrm{II}}$, we anticipated that the conductivity of methanol-infused HKUST-1 would at least somewhat exceed that of bulk methanol (since ethanol does possess a dissociable proton that could in principle be transferred to methanol in the same fashion as proposed for $\mathrm{Cu}^{\mathrm{II}}$-coordinated water). We attribute the lack of observable conductivity enhancement to the difference in acidity for ethanol versus methanol. While the acidity of water $\left(\mathrm{p} K_{\mathrm{a}}=14.0\right)^{23}$ is 30 times greater than that of methanol $\left(\mathrm{p} K_{\mathrm{a}}=15.5\right){ }^{24}$ the acidity of ethanol $\left(\mathrm{p} K_{\mathrm{a}}=15.9\right)^{24}$ is 2.5 times less than that of methanol. Evidently, even with the enhancement of acidity provided by coordination to $\mathrm{Cu}^{\mathrm{II}}$, the conductivity contribution provided by $\mathrm{EtOH}$ is negligible.
Replacing $\mathrm{EtOH}$ with $\mathrm{MeOH}$ as the node-coordinated molecule and subsequently exposing the pore-evacuated material to $\mathrm{MeOH}$ vapor yielded a limiting conductivity of $0.43 \mu \mathrm{S} \mathrm{cm}^{-1}, \sim 2.5$ times that of purified and zeolite-dried bulk methanol and twice that of methanol-infused MeCN-HK (see above). We attribute the observed small enhancement to a modest lowering of the $\mathrm{p} K_{\mathrm{a}}$ of $\mathrm{MeOH}$ upon coordination to $\mathrm{Cu}$.

In the case of pristine-HK, we anticipated that the conductivity would fall midway between that for $\mathrm{H}_{2} \mathrm{O}-\mathrm{HK}$ and $\mathrm{EtOH}-\mathrm{HK}$, since $60 \%$ of the coordinated solvent molecules are water. Instead, upon exposure to $\mathrm{MeOH}$ vapor, poreevacuated "pristine-HK" yielded a limiting conductivity of 0.5 $\mu \mathrm{S} \mathrm{cm}{ }^{-1}$, which is much closer to that of EtOH-HK (Figure 4). At present, we lack a compelling explanation for this interesting observation.

Finally, the fact that noncoordinated proton-labile species are needed to engender significant conductivity was established via two more experiments. In one, $\mathrm{H}_{2} \mathrm{O}-\mathrm{HK}$ was exposed to $n$ hexane vapor and yielded a limiting conductivity more than 5 orders of magnitude below that obtained for $\mathrm{H}_{2} \mathrm{O}-\mathrm{HK}$ containing $\mathrm{MeOH}$ (Figure 4 and Figure $\mathrm{S} 4$ in the $\mathrm{SI})^{25,26}$ The second involved fully solvent-evacuated HKUST-1, which yielded a conductivity below the measurement threshold for our instrumentation.

In summary, postsynthesis modification of HKUST-1 via coordination of $\mathrm{H}_{2} \mathrm{O}$ at open $\mathrm{Cu}^{\mathrm{II}}$ (node) sites led to a large ( $\sim 75$-fold) enhancement in proton conductivity, relative to a version containing nodes modified by acetonitrile, once the material's channels were infused with $\mathrm{MeOH}$. The enhanced conductivity is ascribed to proton donation to $\mathrm{MeOH}$ by coordinated water, where the metal cations serve to enhance the acidity of the water molecules. While the study was limited to several variants of HKUST-1, this new approach to increasing proton conductivity should be transferrable to other MOF materials, including materials that offer open metal sites as components of linkers (e.g., MOFs featuring active-site-accessible metalloporphyrins or -salens as linkers). Acidity enhancements and therefore conductivity enhancements likely could be magnified by applying the strategy to MOFs such as Cr MIL-101 that contain ligand-accessible metal ions with higher charge than the $\mathrm{Cu}^{\mathrm{II}}$ ions of HKUST-1.

\section{ASSOCIATED CONTENT}

\section{S Supporting Information}

Experimental details and electrochemical impedance spectra. This material is available free of charge via the Internet at http://pubs.acs.org.

\section{AUTHOR INFORMATION}

\section{Corresponding Author}

o-farha@northwestern.edu; j-hupp@northwestern.edu

\section{ACKNOWLEDGMENTS}

We thank Prof. Thomas O. Mason and Mr. Chaiya Prasittichai for critical discussions about impedance data and for helpful comments on the manuscript. We gratefully acknowledge the Defense Threat Reduction Agency for support of our work, initially via Grant HDTRA1-08-c-0005 and subsequently via HDTRA1-09-1-0007. We also acknowledge partial support for O.K.F. from the Northwestern University NSEC. 


\section{REFERENCES}

(1) (a) Férey, G. Chem. Soc. Rev. 2008, 37, 191. (b) Yaghi, O. M.; O'Keeffe, M.; Ockwig, N. W.; Chae, H. K.; Eddaoudi, M.; Kim, J. Nature 2003, 423, 705. (c) Horike, S.; Shimomura, S.; Kitagawa, S. Nat. Chem. 2009, 1, 695. (d) Farha, O. K.; Hupp, J. T. Acc. Chem. Res. 2010, 43, 1166.

(2) (a) Li, J. R.; Kuppler, R. J.; Zhou, H. C. Chem. Soc. Rev. 2009, 38, 1477. (b) Lee, C. Y.; Bae, Y. S.; Jeong, N. C.; Farha, O. K.; Sarjeant, A. A.; Stern, C. L.; Nickias, P.; Snurr, R. Q.; Hupp, J. T.; Nguyen, S. T. J. Am. Chem. Soc. 2011, 133, 5228.

(3) (a) Murray, L. J.; Dincă, M.; Long, J. R. Chem. Soc. Rev. 2009, 38, 1294. (b) Farha, O. K.; Yazaydin, A. O.; Eryazici, I.; Malliakas, C. D.; Hauser, B. G.; Kanatzidis, M. G.; Nguyen, S. T.; Snurr, R. Q.; Hupp, J. T. Nat. Chem. 2010, 2, 944. (c) Zhou, H. C.; Zhao, D.; Timmons, D. J.; Yuan, D. Q. Acc. Chem. Res. 2011, 44, 123. (d) Furukawa, H.; Ko, N.; Go, Y. B.; Aratani, N.; Choi, S. B.; Choi, E.; Yazaydin, A. O.; Snurr, R. Q.; O’Keeffe, M.; Kim, J.; Yaghi, O. M. Science 2010, 329, 424.

(4) Ma, L. Q.; Abney, C.; Lin, W. B. Chem. Soc. Rev. 2009, 38, 1248.

(5) Lee, J.; Farha, O. K.; Roberts, J.; Scheidt, K. A.; Nguyen, S. T.; Hupp, J. T. Chem. Soc. Rev. 2009, 38, 1450.

(6) (a) Lu, G.; Hupp, J. T. J. Am. Chem. Soc. 2010, 132, 7832. (b) Allendorf, M. D.; Houk, R. J. T.; Andruszkiewicz, L.; Talin, A. A.; Pikarsky, J.; Choudhury, A.; Gall, K. A.; Hesketh, P. J. J. Am. Chem. Soc. 2008, 130, 14404.

(7) Min, K. S.; Suh, M. P. J. Am. Chem. Soc. 2000, 122, 6834.

(8) (a) Horcajada, P.; Serre, C.; Vallet-Regi, M.; Sebban, M.; Taulelle, F.; Férey, G. Angew. Chem., Int. Ed. 2006, 45, 5974. (b) An, J.; Geib, S. J.; Rosi, N. L. J. Am. Chem. Soc. 2009, 131, 8376. (c) TaylorPashow, K. M. L.; Rocca, J. D.; Xie, Z.; Tran, S.; Lin, W. J. Am. Chem. Soc. 2009, 131, 14261. (d) Della Rocca, J.; Liu, D.; Lin, W. Acc. Chem. Res. 2011, 44, 957-968.

(9) Kreuer, K. D.; Paddison, S. J.; Spohr, E.; Schuster, M. Chem. Rev. 2004, 104, 4637.

(10) (a) Wood, B. C.; Marzari, N. Phys. Rev. B 2007, 76, No. 134301. (b) Yu, R.; De Jonghe, L. C. J. Phys. Chem. C 2007, 111, 11003.

(11) Achmann, S.; Hagen, G.; Kita, J.; Malkowsky, I. M.; Kiener, C.; Moos, R. Sensors 2009, 9, 1574.

(12) (a) Yamada, T.; Morikawa, S.; Kitagawa, H. Bull. Chem. Soc. Jpn. 2010, 83, 42. (b) Shigematsu, A.; Yamada, T.; Kitagawa, H. J. Am. Chem. Soc. 2011, 133, 2034. (c) Taylor, J. M.; Mah, R. K.; Moudrakovski, I. L.; Ratcliffe, C. I.; Vaidhyanathan, R.; Shimizu, G. K. H. J. Am. Chem. Soc. 2010, 132, 14055.

(13) (a) Hurd, J. A.; Vaidhyanathan, R.; Thangadurai, V.; Ratcliffe, C. I.; Moudrakovski, I. L.; Shimizu, G. K. H. Nat. Chem. 2009, 1, 705. (b) Sadakiyo, M.; Yamada, T.; Kitagawa, H. J. Am. Chem. Soc. 2009, 131, 9906. (c) Kobayashi, Y.; Jacobs, B.; Allendorf, M. D.; Long, J. R. Chem. Mater. 2010, 22, 4120.

(14) (a) Farha, O. K.; Mulfort, K. L.; Hupp, J. T. Inorg. Chem. 2008, 47, 10223. (b) Hwang, Y. K.; Hong, D.-Y.; Chang, J.-S.; Jhung, S. H.; Seo, Y.-K.; Kim, J.; Vimont, A.; Daturi, M.; Serre, C.; Férey, G. Angew. Chem., Int. Ed. 2008, 47, 4144. (c) Demessence, A.; D'Alessandro, D. M.; Foo, M. L.; Long, J. R. J. Am. Chem. Soc. 2009, 131, 8784. (d) Farha, O. K.; Spokoyny, A. M.; Mulfort, K. L.; Galli, S.; Mirkin, C. A.; Hupp, J. T. Small 2009, 5, 1727. (e) Shultz, A. M.; Sarjeant, A. A.; Farha, O. K.; Hupp, J. T.; Nguyen, S. T. J. Am. Chem. Soc. 2011, 133, $13252-13255$.

(15) Chui, S. S. Y.; Lo, S. M. F.; Charmant, J. P. H.; Orpen, A. G.; Williams, I. D. Science 1999, 283, 1148.

(16) (a) Wang, X. S.; Ma, S. Q.; Forster, P. M.; Yuan, D. Q.; Eckert, J.; Lopez, J. J.; Murphy, B. J.; Parise, J. B.; Zhou, H. C. Angew. Chem., Int. Ed. 2008, 47, 7263. (b) Hu, Y.; Xiang, S.; Zhang, W.; Zhang, Z.; Wang, L.; Bai, J.; Chen, B. Chem. Commun. 2009, 7551.

(17) Snurr, R. Q.; Yazaydin, A. O.; Benin, A. I.; Faheem, S. A.; Jakubczak, P.; Low, J. J.; Willis, R. R. Chem. Mater. 2009, 21, 1425.

(18) (a) Duren, T.; Bae, Y. S.; Snurr, R. Q. Chem. Soc. Rev. 2009, 38,

1237. (b) Yang, Q. Y.; Zhong, C. L. ChemPhysChem 2006, 7, 1417.

(c) Karra, J. R.; Walton, K. S. Langmuir 2008, 24, 8620.

(19) Prior to dissolution, noncoordinated guest molecules were selectively removed from all samples, including pristine-HK, by drying at ambient temperature for $1 \mathrm{~h}$ under dynamic vacuum. The same treatment was used to remove noncoordinated guest molecules from pristine- $\mathrm{HK}$ (i.e., 60:40 $\mathrm{H}_{2} \mathrm{O}: \mathrm{EtOH}-\mathrm{HK}$ ), $\mathrm{H}_{2} \mathrm{O}-\mathrm{HK}, \mathrm{MeCN}-\mathrm{HK}$, EtOH-HK, and $\mathrm{MeOH}-\mathrm{HK}$ prior to exposure to $\mathrm{MeOH}$ or hexane vapor and assessment of conductivity.

(20) (a) Kanning, W. E.; Bobalek, E. G.; Byrne, J. B. J. Am. Chem. Soc. 1943, 65, 1111. (b) Hartley, H.; Raikes, H. R. J. Chem. Soc. 1925, 127, 524.

(21) (a) Prego, M.; Cabeza, O.; Carballo, E.; Franjo, C. F.; Jimenez, E. J. Mol. Liq. 2000, 89, 233. (b) Prego, M.; Rilo, E.; Carballo, E.; Franjo, C.; Jimenez, E.; Cabeza, O. J. Mol. Liq. 2003, 102, 83.

(22) (a) Allison, J. W.; Angelici, R. J. Inorg. Chem. 1971, 10, 2233. (b) Groves, J. T.; Dias, R. M. J. Am. Chem. Soc. 1979, 101, 1033. (c) Menger, F. M.; Gan, L. H.; Johnson, E.; Durst, D. H. J. Am. Chem. Soc. 1987, 109, 2800.

(23) CRC Handbook of Chemistry and Physics, 90th ed.; Lide, D. R., Ed.; CRC Press: Boca Raton, FL, 2010.

(24) Ballinger, P.; Long, F. A. J. Am. Chem. Soc. 1960, 82, 795.

(25) The most prosaic interpretation of the experiment is that even this tiny conductivity is due mainly to residual noncoordinated water or methanol rather than to $n$-hexane.

(26) Attempts to extend the study to water as the guest molecule yielded samples displaying no measurable conductivity. Subsequent PXRD measurements revealed that prolonged exposure to water vapor $(\sim 2 \mathrm{~h})$ resulted in an almost complete loss of MOF crystallinity. To the extent that the loss entails pore collapse, this would account for the absence of measurable conductivity. 